1

Journal of Materials Science manuscript No.

(will be inserted by the editor)

\title{
The mechanical behaviour of poly(vinyl butyral) at different strain magnitudes and strain rates
}

\author{
P. A. Hooper · B. R. K. Blackman · J. P. Dear
}

Received: date / Accepted: date

\begin{abstract}
The mechanical behaviour of poly(vinyl butyral) (PVB) at small $(<0.1 \%)$ and large strains ( $>200 \%$ ) is investigated experimentally over a range of strain rates in order to provide data for the development and validation of constitutive models. The small-strain response is investigated using dynamic mechanical analysis at frequencies from $1 \mathrm{~Hz}$ to $100 \mathrm{~Hz}$ and temperatures from $-80^{\circ} \mathrm{C}$ to $70^{\circ} \mathrm{C}$. It is found that a generalized Maxwell model adequately describes the material behaviour in the small-strain regime. The large-strain response is investigated using a high-speed servo hydraulic test machine at strain-rates from $0.2 \mathrm{~s}^{-1}$ to $400 \mathrm{~s}^{-1}$. It is found that the PVB response is characterised by a time-dependent steep initial rise in stress followed by a hyperelastic type response until failure. No current material model completely captures this time-dependent behaviour at large-strains.
\end{abstract}

Keywords PVB · Poly(vinyl butyral) $\cdot$ Laminated glass $\cdot$ DMA $\cdot$ Large strain $\cdot$ High strain-rate · Viscoelasticity

P. A. Hooper · B.R.K. Blackman · J. P. Dear

Department of Mechanical Engineering, Imperial College London, Exhibition Road, London, SW7 2AZ, UK

Tel.: +4420 75947128

E-mail: p.hooper07@imperial.ac.uk 


\section{Introduction}

Polyvinyl butyral (PVB) is primarily used as an interlayer material in the manufacture of laminated glass. Its mechanical response is highly non-linear, time dependent and it is capable of undergoing extensions to several times its initial length and recovering without significant permanent deformation. The behaviour of PVB at two distinct strain magnitudes are of practical interest. Firstly, the small-strain behaviour plays an important role in determining the bending behaviour of uncracked laminated glass panes. Secondly, the large-strain behaviour is of interest in cracked laminated glass where the PVB acts as bridge between glass fragments and can undergo large tensile extensions. The mechanical response at different rates of strain is also of significant importance due to applications ranging from quasi-static loading through to impact, ballistic and blast loading regimes.

Bennison et al. [1] and van Duser et al. [2] have investigated the small-strain behaviour of a Dupont Butacite interlayer in the development of a finite element model to predict the behaviour of laminated glass plates subject to wind pressure loading. They included viscoelastic effects by using a generalized Maxwell series to account for the time-dependent shear modulus of the interlayer. Terms in the Maxwell model were determined experimentally using dynamic mechanical analysis. Variation in shear modulus at different temperatures was also taken into account by using the Williams-Landel-Ferry (WLF) equation [3] to shift the time dependent shear modulus curve to a different temperature. The mechanical behaviour of PVB at large-strains has not been widely reported in the literature.

In this paper the behaviour of a single grade of PVB is investigated experimentally over a wide range of strain magnitudes and strain rates. The behaviour over these ranges needs to be fully understood before physically based models of laminated glass (particularly after the glass plies fracture) and other composites containing PVB can be developed. 


\section{Methods}

The mechanical behaviour of PVB was investigated using two experimental methods. The small-strain behaviour was investigated using dynamic mechanical analysis (DMA) at frequencies from $1 \mathrm{~Hz}$ to $100 \mathrm{~Hz}$ and temperatures from $-80^{\circ} \mathrm{C}$ to $70^{\circ} \mathrm{C}$. The large-strain behaviour was investigated using a servo hydraulic tensile test machine at displacement rates between $0.01 \mathrm{~m} / \mathrm{s}$ and $15 \mathrm{~m} / \mathrm{s}$. The interlayer material tested was Saflex PVB produced by Solutia Inc. with product number RB-41.

\subsection{Small-strain behaviour}

The small-strain viscoelastic behaviour of PVB is of interest when considering the response of a laminated glass pane to loading before the glass plies fracture. Under these conditions the strain in the PVB is limited by the failure strain of the glass plies (typically $0.1 \%$ ). The small-strain viscoelastic response has been investigated using DMA. The following sections cover some background information on viscoelasticity, the DMA experimental technique and analysis methods used.

\section{Linear viscoelasticity}

The viscoelastic properties of a material can be investigated by subjecting a sample to an oscillatory load. When a viscoelastic material is subjected to an oscillating load the strain $\varepsilon$ lags behind the applied stress $\sigma$ due to the viscous component of the material response. Figure 1a shows an applied sinusoidal stress and the resulting out-of-phase strain response with a phase angle $\delta$. It is useful to define two moduli which correspond to the elastic and viscous components of stress. Figure $1 \mathrm{~b}$ shows the stress signal decomposed into a component in phase with the strain and a component out-of-phase with the strain. 
4

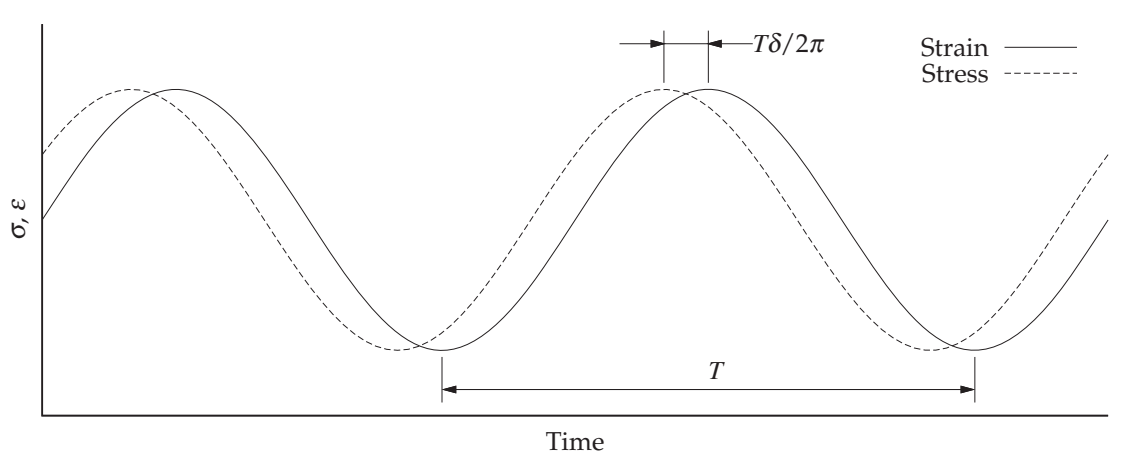

(a) Lag in stress.

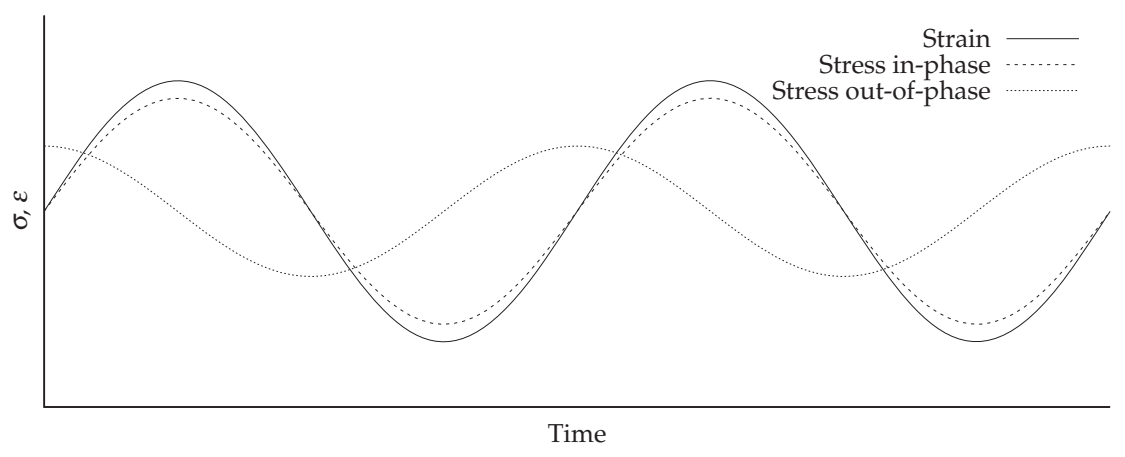

(b) Stress components.

Fig. 1: Sinusoidal stress and strain for a linear viscoelastic material.

The amplitude of the stress in-phase with the strain divided by the strain amplitude is referred to as the storage modulus and is denoted by $E^{\prime}$ in tension and $G^{\prime}$ in shear. The amplitude of the stress out-of-phase with the strain divided by the strain amplitude is referred to as the loss modulus and is denoted by $E^{\prime \prime}$ in tension and $G^{\prime \prime}$ in shear. The ratio of the moduli is equal to the tangent of the phase angle

$$
\frac{E^{\prime \prime}}{E^{\prime}}=\frac{G^{\prime \prime}}{G^{\prime}}=\tan \delta
$$




\section{Dynamic mechanical analysis}

Fig. 2: DMA tensile fixture.

For $\tan \delta=0$ the stress and strain are in-phase (the loss modulus is equal to zero) and the material behaviour is purely elastic. For $\tan \delta=1$ the viscous component of stress is as large as the elastic component and the stress and strain are $45^{\circ}$ out-of-phase. At a phase angle of $90^{\circ}$ the storage modulus is equal to zero and the material behaviour is purely viscous.

In dynamic mechanical analysis (DMA) a sinusoidal strain is applied to a sample and the resulting stress signal is measured in order to calculate storage modulus, loss modulus and $\tan \delta$. This is usually performed over ranges of frequencies and temperatures to characterise a material at different time scales. A TA Instruments Q800 DMA machine was used to test the small-strain viscoelastic behaviour of PVB in extension. Figure 2 shows the tensile fixture used to apply oscillatory strains to the sample. 
In this fixture the top of the sample is held stationary between grips and the bottom of the sample is connected to a drive shaft which oscillates up and down. The initial length of the sample $l_{0}$ was $16 \mathrm{~mm}$, the width $w$ was $4.45 \mathrm{~mm}$ and the thickness was $1.52 \mathrm{~mm}$. A small preload was applied to the sample to ensure that it did not buckle when oscillated. The stress in the sample was then calculated from the cross sectional area and the applied force. The strain was found from the original length of the sample and the displacement of the drive shaft. The PVB was tested with a strain amplitude of $0.1 \%$ at three frequencies; $1 \mathrm{~Hz}, 10 \mathrm{~Hz}$ and $100 \mathrm{~Hz}$.

The test fixture shown in Fig. 2 was enclosed inside a chamber so that the temperature could be controlled and varied. A liquid nitrogen cooling stage was used to reduce the temperature in the chamber to below ambient and an internal heating element was used to raise the temperature above ambient. A thermocouple placed close to the sample was used to provide feedback for the temperature controller. The PVB was tested under isothermal conditions at $5^{\circ} \mathrm{C}$ temperature increments from $-80^{\circ} \mathrm{C}$ to $70^{\circ} \mathrm{C}$. At each temperature increment, data was collected at the three test frequencies.

\section{Time-temperature superposition}

The Time-Temperature Superposition (TTS) principle states that the moduli (and other viscoelastic functions) measured over a range of frequencies at one temperature can be superposed with the moduli measured over a range of frequencies at a different temperature. That is to say there is an equivalence between time and temperature for the material response. TTS can be used to expand the tested frequency range by performing tests at different temperatures and reducing the results to a single reference temperature $T_{0}$. 
The reduction of data to a single temperature is performed by shifting the frequency values collected at one temperature by a factor, $a_{T}$, until the curve overlaps with the curve at the reference temperature. The shift factor is equal to

$$
a_{T}=\frac{\omega_{0}}{\omega_{T}}
$$

where $\omega_{0}$ is the frequency that gives a particular response at the reference temperature and $\omega_{T}$ is the frequency that gives the same response at another temperature. Calculating the shift factors for each test temperature allows a master curve to be produced where all the data have been reduced to a single reference temperature. This technique was applied to the data acquired using DMA to expand the frequency range beyond the machine capabilities which were between $0.01 \mathrm{~Hz}$ and $200 \mathrm{~Hz}$. The shift factors of the data were determined by manually shifting the data to a reference temperature of $20^{\circ} \mathrm{C}$ using the Rheology Advantage Data Analysis Software provided by TA Instruments.

The Williams-Landel-Ferry (WLF) equation [3] is an empirical relation between temperature and shift factors of the form

$$
\log a_{T}=-\frac{C_{1}\left(T-T_{0}\right)}{C_{2}+T-T_{0}}
$$

where $C_{1}$ and $C_{2}$ are constants. The manually determined shift factors were fitted to the WLF equation using nonlinear regression to find $C_{1}$ and $C_{2}$. This was done for shift factors between $0^{\circ} \mathrm{C}$ and $70^{\circ} \mathrm{C}$. Below $0^{\circ} \mathrm{C}$ the PVB was found to be in the glassy regime and the shift factors were no longer described by the WLF equation. The shift factors were recalculated using the WLF equation to provide a refined master curve. Once a master curve has been generated the WLF equation can be used to extrapolate it to different reference temperatures. 


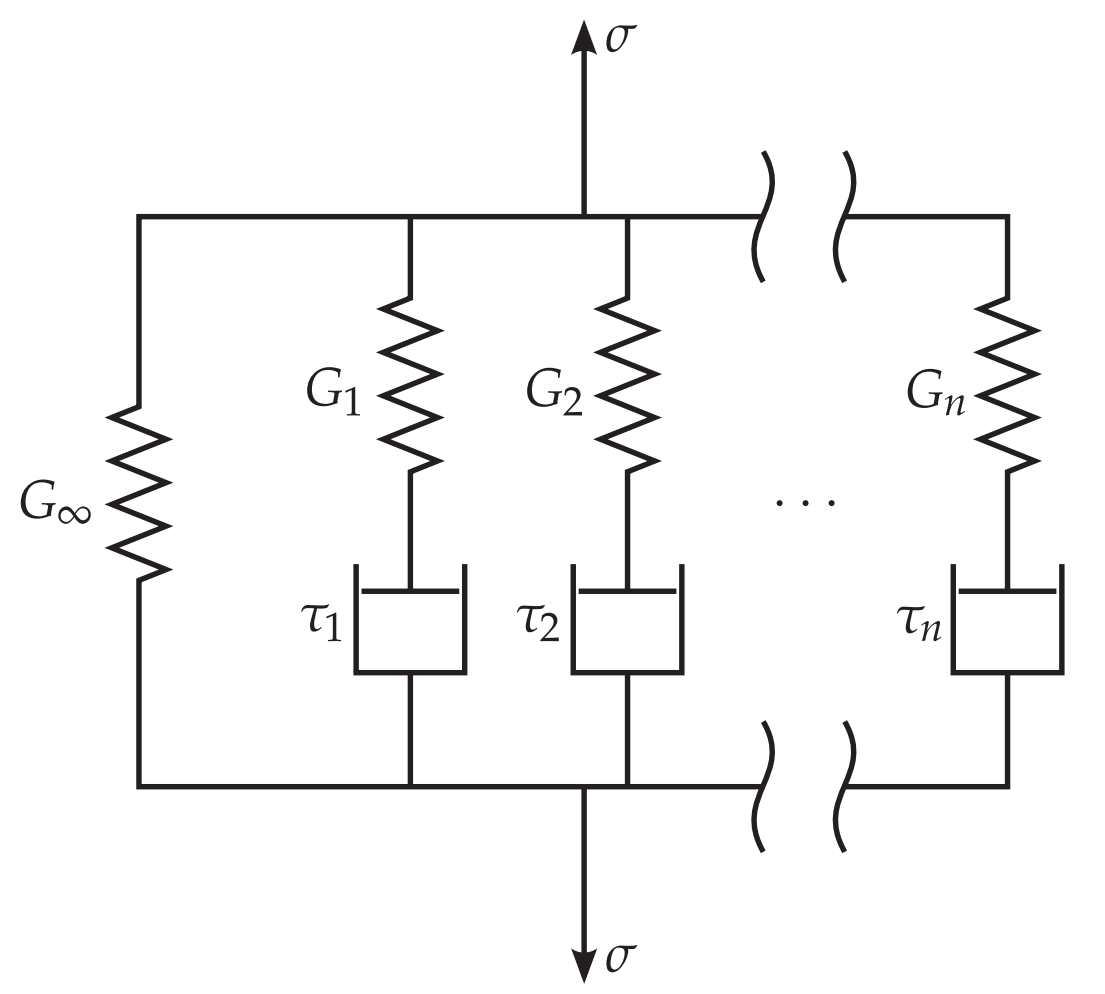

Fig. 3: Generalized Maxwell viscoelastic material model.

\section{Generalized Maxwell model}

The small-strain viscoelastic behaviour of many polymers can be described using the generalized Maxwell model [4]. The model is shown in Fig. 3 and consists of a series of elastic spring and viscous damper pairs in parallel. Under rapid loading the damping elements do not have time to deform and the stiffness is defined by the summation of the spring elements. For infinitely slow loading the stresses in the damping elements are zero and the stiffness is defined by the single undamped spring. This model is commonly used to define viscoelastic behaviour in finite element programs such as Abaqus.

The Generalized Maxwell model can be defined mathematically by 


$$
G(t)=G_{\infty}+\sum_{i=1}^{n} G_{i} e^{-t / \tau_{i}}
$$

where $G(t)$ is the shear relaxation modulus and is a function of time $t, G_{\infty}$ is the long term shear modulus and $G_{i}$ and $\tau_{i}$ are the shear modulus and relaxation times associated with each spring and damper pair. The instantaneous shear modulus $G_{0}$ is defined as

$$
G_{0}=G_{\infty}+\sum_{i=1}^{n} G_{i}
$$

The frequency data collected using DMA and TTS were converted to relaxation data using the approximation [4]

$$
G(t)=G^{\prime}(\omega)-0.40 G^{\prime \prime}(0.40 \omega)+\left.0.014 G^{\prime \prime}(10 \omega)\right|_{\omega=1 / t}
$$

where $\omega$ is the frequency in radians per second. The measured tensile storage and loss functions $E^{\prime}(\omega)$ and $E^{\prime \prime}(\omega)$ were converted to $G^{\prime}(\omega)$ and $G^{\prime \prime}(\omega)$ using the relation $E=3 G$ (assuming an incompressible material) [4]. Evaluation of the loss modulus at the required frequencies was performed using linear interpolation. Nonlinear regression was used to fit the generalized Maxwell model to the shear relaxation modulus data and determine the values of $G_{\infty}, G_{i}$ and $\tau_{i}$.

\subsection{Large strain tensile tests}

The large strain behaviour of PVB is of interest when considering the response of cracked laminated glass to loads such as those from blast and impact. In these situations the PVB acts as a bridging ligament between glass fragments and can experience large extensions before failing. A servo-hydraulic tensile test machine was used to test PVB samples in tension at displacement rates between $0.01 \mathrm{~m} / \mathrm{s}$ and $15 \mathrm{~m} / \mathrm{s}$. 


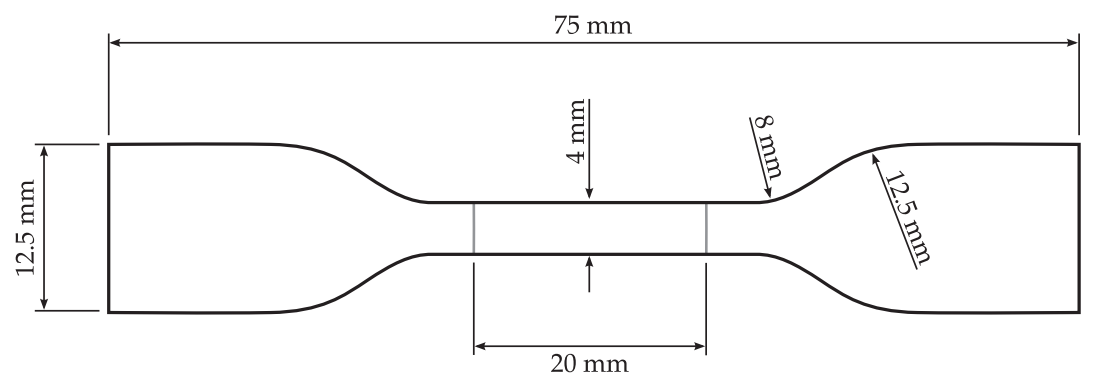

Fig. 4: PVB tensile test sample dimensions.

PVB tensile specimens

Tensile test specimens were cut from sheet PVB of thickness $0.76 \mathrm{~mm}$ (Solutia product number RB-41) using a die. The sample geometry used was that of specimen Type 2 outlined in BS ISO 37:2005 [5] and is shown in Fig. 4. The specimens were cut in perpendicular directions to check for anisotropy in the mechanical response. Anisotropic behaviour could not be distinguished from between-sample variability so the material was assumed to be isotropic. The $20 \mathrm{~mm}$ central test section length was marked with thin black lines using a permanent marker pen prior to testing to enable the strain to be monitored during the test using a high-speed camera. Digital callipers were used to measure the thickness and width of the test section at three locations to an accuracy of $0.03 \mathrm{~mm}$.

\section{Test equipment}

An Instron VHS high strain-rate test machine was used to load the PVB test samples in tension. The test samples were connected to the test machine through lightweight titanium alloy grips. All connecting components between the sample and load cells were kept as light as possible to minimise transient forces under acceleration. A piezoelectric load-cell (Model 
222B manufactured by PCB Piezotronics Inc) was used to measure load at displacement rates above $0.1 \mathrm{~m} / \mathrm{s}$. At slower rates it was found that the discharge time constant of the load-cell and amplifier circuit was too short with respect to the rate at which the force was changing, resulting in drift in the recorded signal. To mitigate this problem a strain gauge load-cell was used at displacement rates of $0.1 \mathrm{~m} / \mathrm{s}$ and slower since strain gauges do not suffer from the loss of charge as piezoelectric load cells do.

The top of the sample was connected to the test machine actuator through a lost-motion device as shown in Fig. 5. The device gives the actuator enough travel to accelerate to the desired test velocity before loading the sample. Vibrations occurring at the onset of loading were damped out with a thin rubber washer. A support was provided to prevent the PVB samples from collapsing under the weight of the loss motion device and to ensure they were taught prior to loading. The test temperature was the ambient room temperature which was $25 \pm 3^{\circ} \mathrm{C}$

The force from both load cells and the actuator displacement were recorded by an Imatek C2008 data acquisition system. The position of the actuator was tracked internally by the test machine using a linear variable differential transformer (LVDT). A high-speed camera was used to record extension and strain. An automated lighting system that switched on just prior to loading was used to minimise heating of the sample. Both the high-speed camera and the data acquisition hardware were triggered by the actuator displacement, just prior to the end of travel of the lost-motion device, to ensure synchronous recording.

\subsubsection{Optical strain measurement}

Images of the sample deformation captured by high-speed camera were post-processed to calculate strain in the sample. A software program was developed using the OpenCV computer vision library to track the position of lines on the samples over time [6]. The Lucas- 


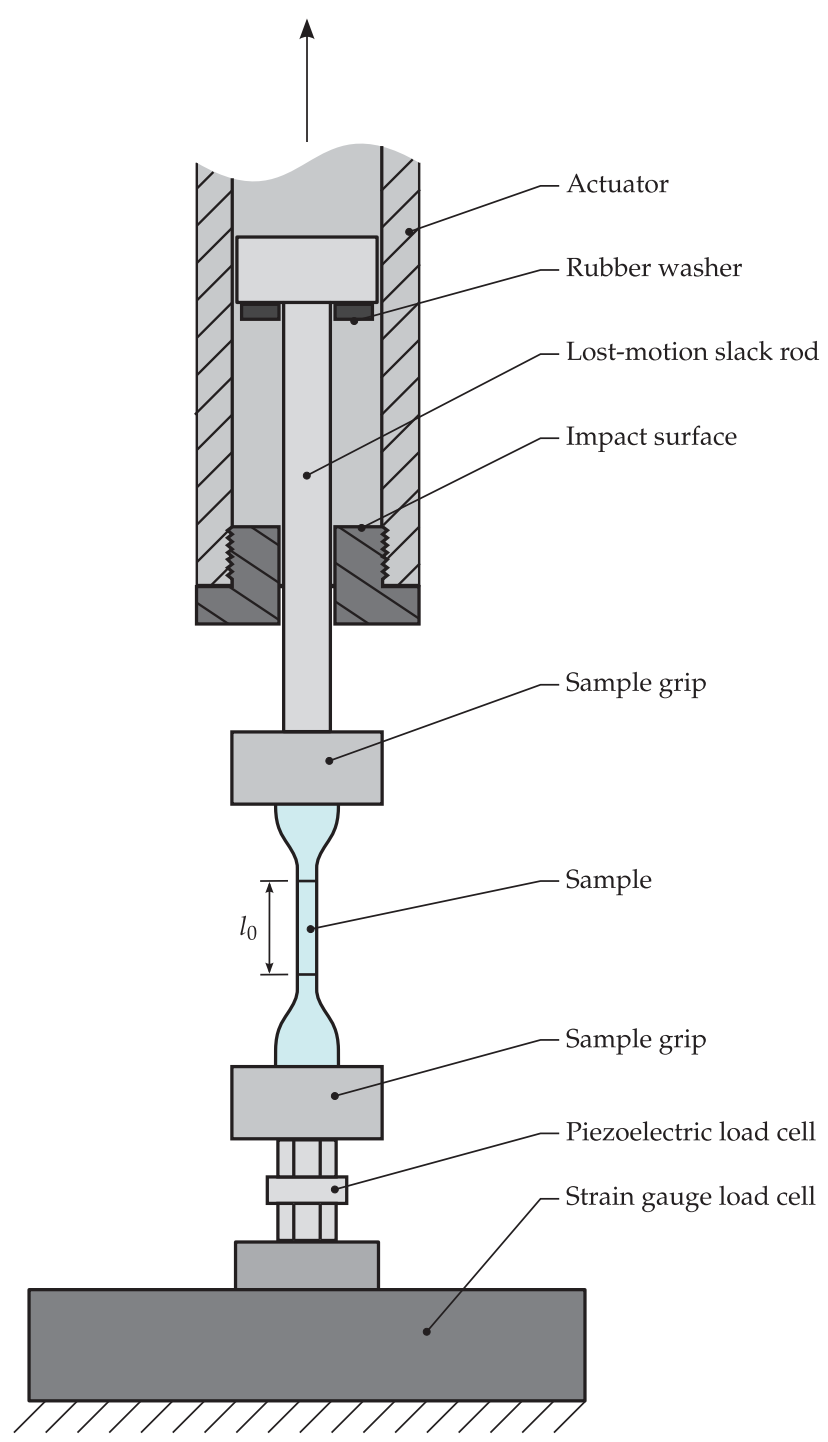

Fig. 5: PVB tension test setup with actuator cutaway showing lost-motion device.

Kanade (LK) method of feature tracking was used to track the motion of selected features between images [7]. The four edges created by the two lines marked on the test specimens were tracked as shown by the green dots in Fig. 6 . The test section length in each frame was determined from the average of the distance between the two outer markers and the two 


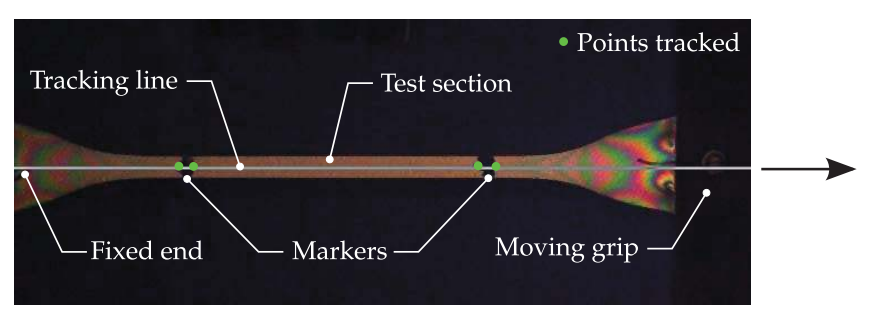

Fig. 6: Tracking of test section length on a PVB tensile test sample.

inner markers before the specimen was loaded. The engineering strain was then calculated using the original length, determined from the frame just prior to the start of loading and the difference in length in all subsequent frames. No attempt was made to calibrate and correct for lens distortion, which was found to be less than a pixel over the specimen gauge length. An image of a steel rule positioned in place of a test specimen was analysed and no deviation in the scale length at the image centre and at the image edge could be found.

\section{Data analysis}

A typical engineering stress-strain response for a PVB tensile test is shown in Fig. 7. The strain in the sample was calculated from tracking markers on the sample in images captured by the high-speed camera. The images were captured at known intervals from the time the camera was triggered, enabling the calculated strains to be easily synchronised with the force-time data. However, the force was captured at a higher frequency than the images used to calculate strain. It was therefore necessary to interpolate the strain data to the times at which the force data was sampled. The stress at failure, $\sigma_{\mathrm{f}}$, and the strain to failure, $\varepsilon_{\mathrm{f}}$, were calculated at the time of maximum force. Two moduli were also calculated, the smallstrain modulus, $E_{0}$, and the large strain modulus $E_{20 \%}$ corresponding to the gradient of the stress-strain curve at 20\% strain. The stress at the point where the two moduli lines intersect, 


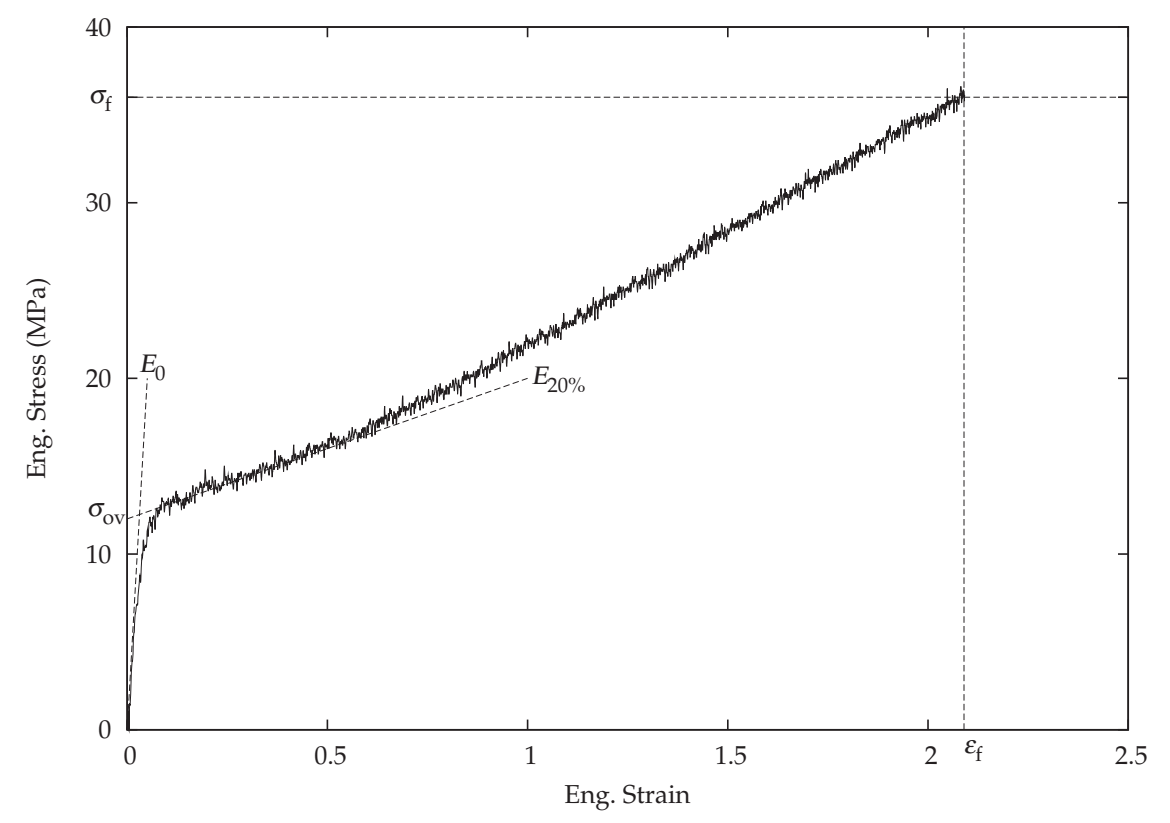

Fig. 7: Typical stress-strain curve from a PVB tensile test.

as shown in Fig. 7, is defined as the overstress $\sigma_{\mathrm{ov}}$ and is a measure of the increase in stress due to viscous effects.

When considering large deformations it is useful to define new measures of stress and strain in addition to their engineering definitions. For most materials a large tensile extension is accompanied by a reduction in cross-sectional area, resulting in an increase in stress. The true stress $\sigma_{\mathrm{t}}$ takes this reduction in area into account by using the current cross-sectional area in its definition rather than the original cross-section area. It is often related to the engineering stress $\sigma$ by assuming that the deformation occurs under a condition of constant volume and uniform strain (that is no necking). This results in the relation

$$
\sigma_{\mathrm{t}}=\sigma(1+\varepsilon)
$$


where $\varepsilon$ is the engineering strain. This assumption is usually valid for rubbery materials since Poisson's ratio is approximately $0.5[8,9]$. The extension ratio, or stretch, $\lambda$ is defined as the ratio of current length $l$ to initial length $l_{0}$ and is related to the engineering strain by

$$
\lambda=\frac{l}{l_{0}}=1+\frac{\Delta l}{l_{0}}=1+\varepsilon
$$

These definitions of true stress and stretch are commonly used in hyperelastic constitutive models.

\section{Results}

\subsection{Small-strain behaviour}

The tensile storage and loss modulus of PVB measured using DMA are presented as a function of temperature in Fig. 8. At temperatures below approximately $5^{\circ} \mathrm{C}$ the PVB was found to be in the glassy region and the storage modulus was in the order of $1 \mathrm{GPa}$. Between $5^{\circ} \mathrm{C}$ and $10^{\circ} \mathrm{C}$ the modulus began to drop rapidly in magnitude as the PVB entered its transition region. At temperatures above approximately $40^{\circ} \mathrm{C}$ the PVB was in the rubbery region and the storage modulus dropped to the order of $1 \mathrm{MPa}$. The effect of frequency can be seen as a shift of the curve along the temperature axis. An increase in frequency increased the temperature at which the transition region occurred.

The loss modulus in the glassy region was relatively constant and was in the order of $100 \mathrm{MPa}$. This was approximately one tenth of the storage modulus and corresponds to a phase angle of $6^{\circ}$ between the stress and strain. In the transition zone the loss modulus was of the same order of magnitude as the storage modulus and in some cases exceeded it, corresponding to a phase angle of approximately $45^{\circ}$ between the stress and strain. The viscoelastic behaviour of PVB is therefore much more pronounced in the transition region. 

cides with its transition region.

Figure 9 shows the storage and loss moduli that have been reduced to a reference temperature of $20^{\circ} \mathrm{C}$ using TTS and the WLF equation. It shows that the material enters the glassy region at frequencies of approximately $10^{4} \mathrm{rad} / \mathrm{s}$ and is in the rubbery region at frequencies below $1 \mathrm{rad} / \mathrm{s}$. An approximation between strain rate and angular frequency can be made by representing the sinusoidal loading as a triangular wave form. In this case the strain rate $\dot{\varepsilon}$ and angular frequency $\omega$ are related by

$$
\dot{\varepsilon}=\frac{\varepsilon_{0}}{\pi} \omega
$$

where $\varepsilon_{0}$ is the strain amplitude ( $\varepsilon_{0}=0.001$ here). The PVB therefore shows glassy behaviour for strain rates above $3.2 \mathrm{~s}^{-1}$ and rubbery behaviour at strain rates below $3.2 \times$ $10^{-4} \mathrm{~s}^{-1}$ for a temperature of $20^{\circ} \mathrm{C}$.

The shift factors and WLF equation fit used to reduce the data to a reference temperature of $20^{\circ} \mathrm{C}$ are shown in Figure 10 . The WLF equation shows good agreement with the manually determined shift factors. The WLF constants were determined to be $C_{1}=8.87$ and $C_{2}=55.5^{\circ} \mathrm{C}$ using nonlinear regression. The WLF equation can be used to shift the reduced data to a new reference temperature. At a reference temperature of $25^{\circ} \mathrm{C}$ the data would be shifted approximately one decade higher on the frequency scale. The strain rate required to produce glassy behaviour would increase at this higher reference temperature. Similarly a reference temperature of $15^{\circ} \mathrm{C}$ would correspond to a shift of approximately one decade lower on the frequency scale, reducing the strain rate required to produce glassy behaviour.

The shear relaxation modulus calculated using Equation 6 is plotted as a function of time in Fig. 11. The generalized Maxwell fit determined using nonlinear regression is also 


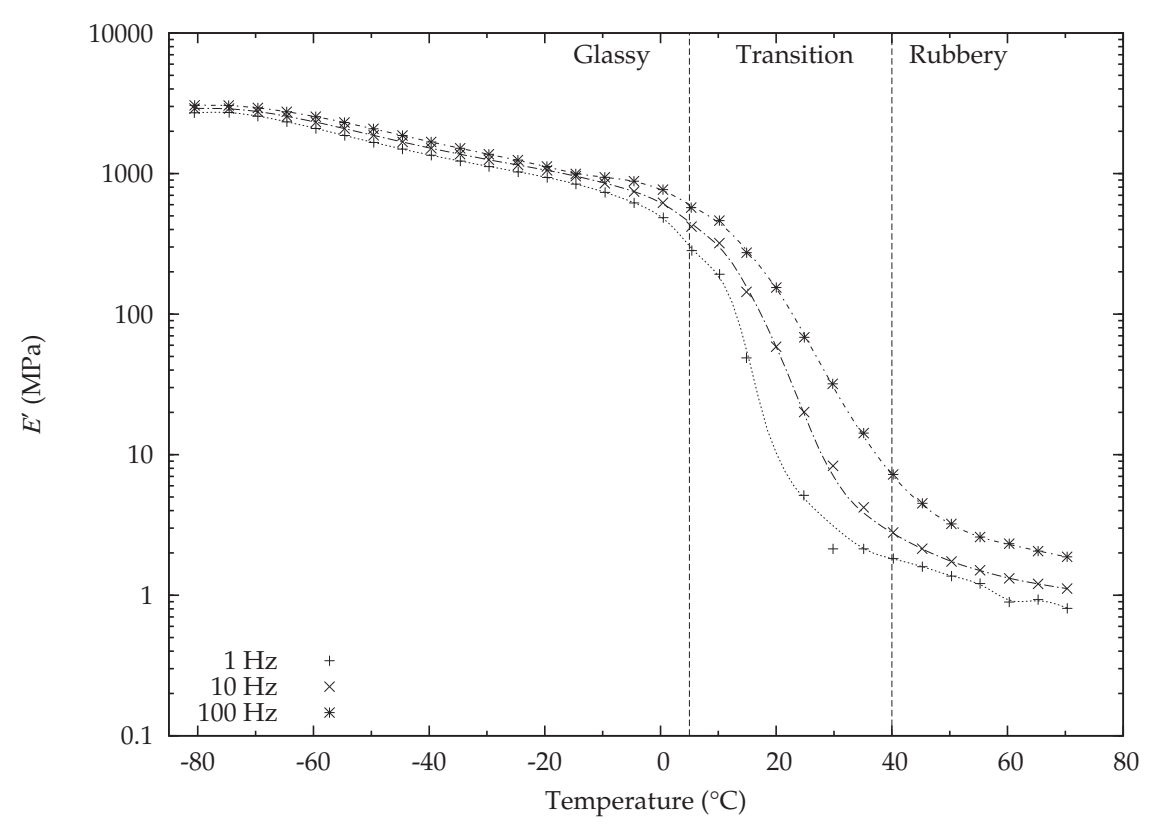

(a) Storage modulus.

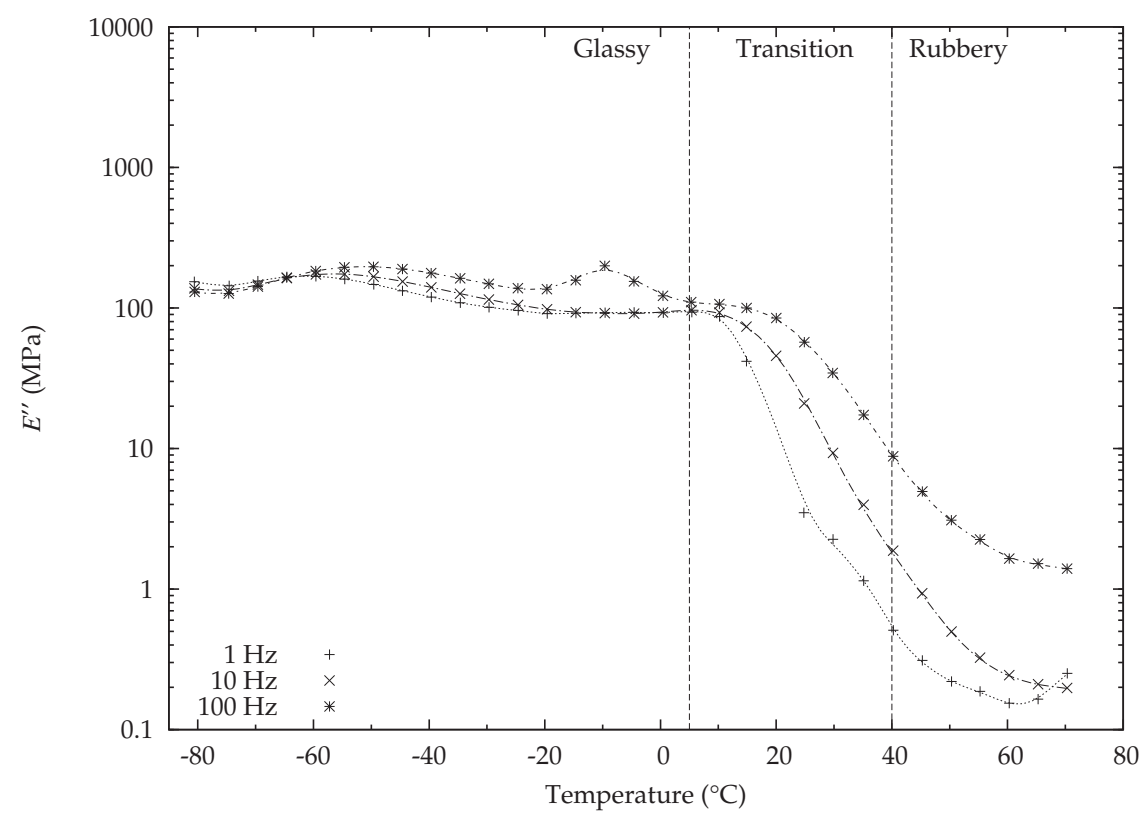

(b) Loss modulus.

Fig. 8: Tensile storage and loss moduli vs temperature for PVB. 


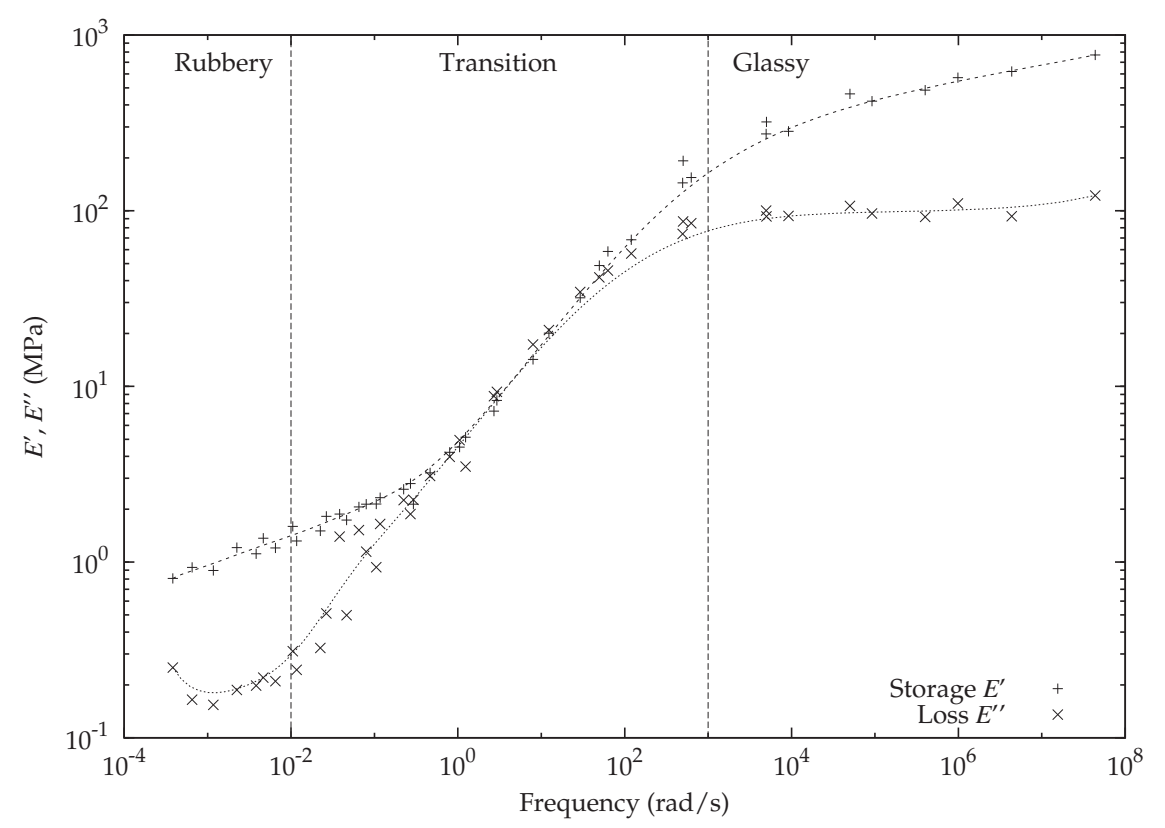

Fig. 9: Tensile storage and loss moduli vs frequency reduced to a temperature of $20^{\circ} \mathrm{C}$.

shown. It was found that six Maxwell elements were enough to describe the shear relaxation modulus over this time scale. Table 1 gives the calculated generalized Maxwell material constants. These parameters can be used in finite element models to include viscoelastic effects at small strains.

\subsection{High strain-rate tensile tests}

A typical time history for a high strain-rate tensile test on PVB is shown in Fig. 12. The figure shows engineering stress, strain and strain rate for a sample tested at $1 \mathrm{~m} / \mathrm{s}$. The stress trace shows a steep initial rise in stress after slack in the lost motion device has been taken up. After the stress reached around $10 \mathrm{MPa}$ the rate at which the stress was increasing slowed by a factor of approximately 10 . The stress continued to increase until failure at a stress of 
Table 1: Generalized Maxwell model terms.

\begin{tabular}{ccc}
\hline$i$ & $G_{i} / G_{0}$ & $\tau_{i}(\mathrm{~s})$ \\
\hline 1 & 0.49016 & $2.45 \times 10^{-5}$ \\
2 & 0.40844 & $2.21 \times 10^{-3}$ \\
3 & 0.08522 & $4.98 \times 10^{-2}$ \\
4 & 0.01389 & $6.24 \times 10^{-1}$ \\
5 & 0.00159 & $2.49 \times 10^{1}$ \\
6 & 0.00200 & $1.00 \times 10^{3}$ \\
\hline
\end{tabular}

* Instantaneous shear modulus $G_{0}=178 \mathrm{MPa}$, long-term shear modulus

$G_{\infty}=0.125 \mathrm{MPa}$

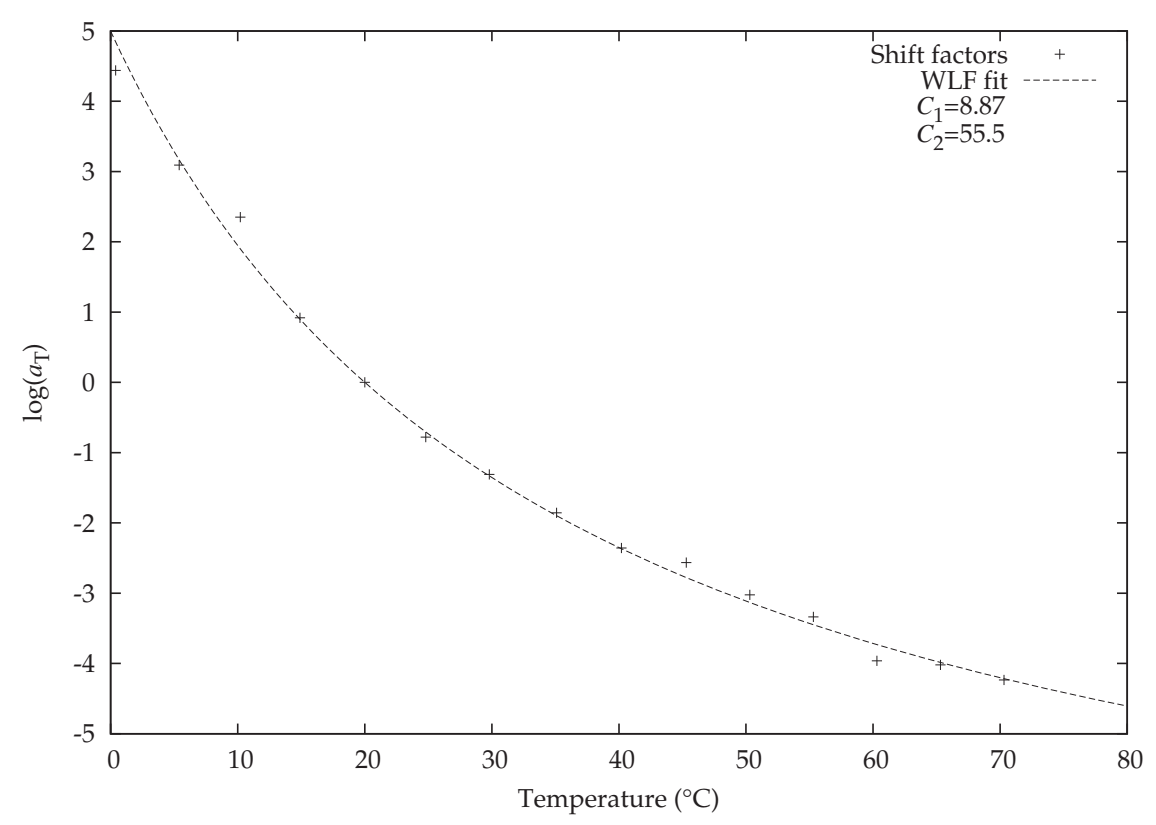

Fig. 10: Manually determined shift factors and the WLF equation fit used to reduce data to a temperature of $20^{\circ} \mathrm{C}$.

$$
G_{\infty}=0.125 \mathrm{MPa}
$$




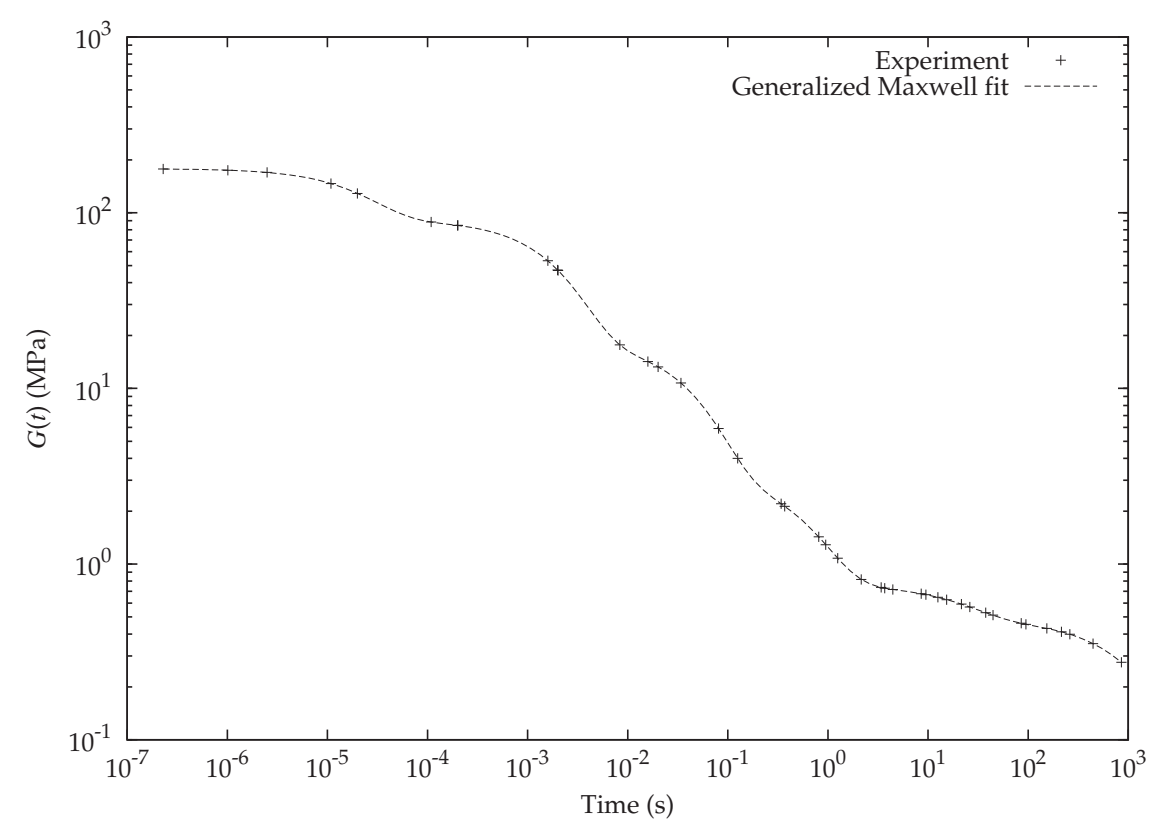

Fig. 11: Shear relaxation curve at a reference temperature of $20^{\circ} \mathrm{C}$.

$33 \mathrm{MPa}$ and a strain of $220 \%$. The strain rate during the test began at $27 \mathrm{~s}^{-1}$ and slowed at an approximately linear rate to $20 \mathrm{~s}^{-1}$ at the time of failure. Small oscillations in the strain rate can be seen at a time of $0.07 \mathrm{~s}$, resulting in small oscillations in the recorded stress. These were a result of small oscillations in the actuator velocity.

The drop in gradient at $10 \mathrm{MPa}$ is not a sign that the material has yielded. Almost all of the extension was recoverable, with samples returning to within $2.5 \%$ of the original gauge length after the test. The initial steep rise in stress is a result of the viscous component of the material response and depends on the applied strain rate.

Figure 13 shows engineering stress-strain curves for PVB samples tested at strain rates between $0.2 \mathrm{~s}^{-1}$ and $400 \mathrm{~s}^{-1}$. Curves at strain rates of $8 \mathrm{~s}^{-1}$ and $200 \mathrm{~s}^{-1}$ are not presented for clarity. The plot shows that the stress-strain response of PVB has a strong strain rate dependence. At a strain rate of $0.2 \mathrm{~s}^{-1}$ the material behaves similarly to a hyperelastic ma- 


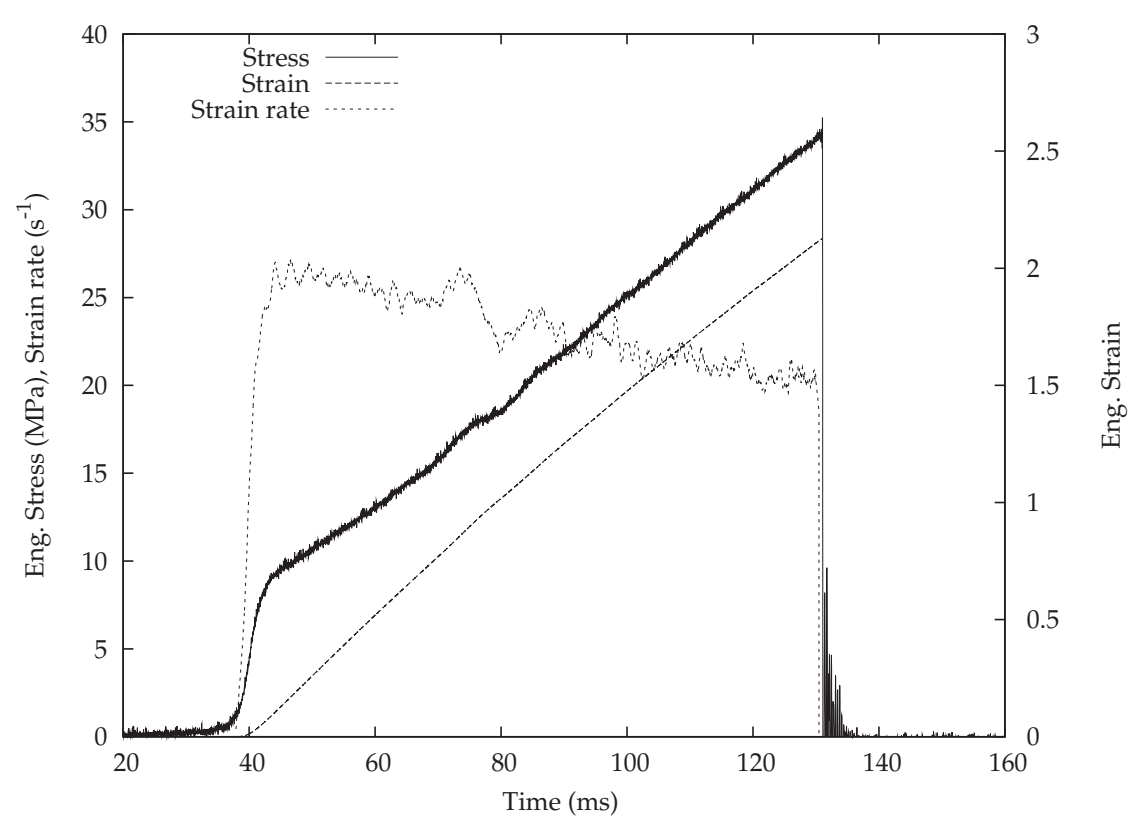

Fig. 12: Engineering stress, strain and strain rate time histories for a test at $1 \mathrm{~m} / \mathrm{s}$.

terial, showing large non-linear deformation up to the point of failure. At higher strain rates the curves show an initial gradient that increases with strain rate. Above strains of $10 \%$ the curves all have similar shapes except for the stress offset resulting from the steep initial rise in stress. This suggests that the small-strain behaviour is greatly affected by the viscous response where as the large-strain behaviour is not. At a strain rate of $400 \mathrm{~s}^{-1}$ small oscillations can be seen in the trace after the steep initial rise in stress. The period of these oscillations was approximately $290 \mu$ s and matched the natural period of the load-cell and grips as determined from oscillations after sample break (see Fig. 15).

\section{Small-strain modulus}

The small-strain modulus, $E_{0}$, was calculated from the initial steep gradient section of each stress-strain curve and is shown as a function of strain rate in Fig. 14. The small-strain 


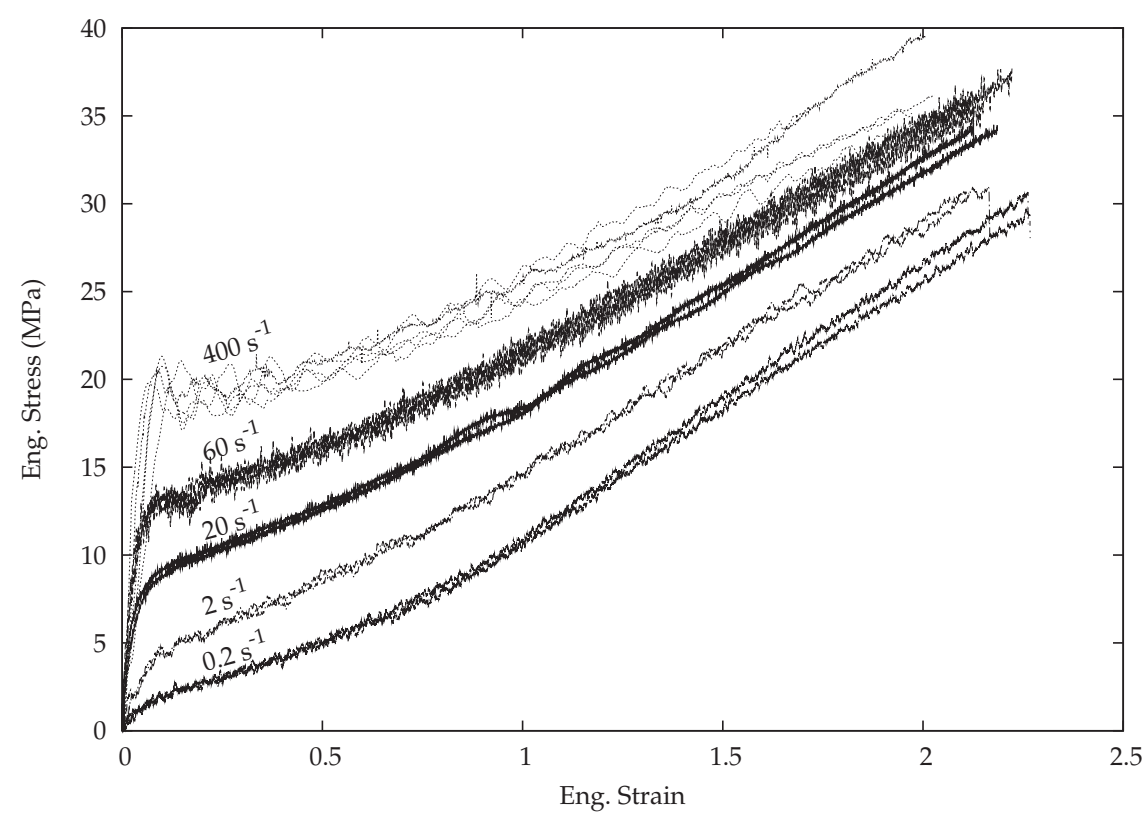

Fig. 13: Summary of engineering stress vs engineering strain at different strain rates.

modulus varies between $20 \mathrm{MPa}$ and $1 \mathrm{GPa}$ over strain rates between $0.2 \mathrm{~s}^{-1}$ and $400 \mathrm{~s}^{-1}$. The modulus values observed between $0.2 \mathrm{~s}^{-1}$ and $60 \mathrm{~s}^{-1}$ are approximately proportional to the square root of strain rate

$$
E_{0}=E_{0,0}\left(\frac{\dot{\varepsilon}}{\dot{\varepsilon}_{0}}\right)^{1 / 2}
$$

where $E_{0,0}$ is the small-strain modulus at reference strain rate $\dot{\varepsilon}_{0}$. The small-strain reference modulus was determined using nonlinear regression and was found to be $E_{0,0}=$ $51 \pm 3 \mathrm{MPa}$ at a reference strain rate, $\varepsilon_{0}$, of $1 \mathrm{~s}^{-1}$. The measured small-strain modulus values remain within $20 \%$ of this empirical fit except at strain rates of $200 \mathrm{~s}^{-1}$ and above. 
Fig. 14: Log-log plot of tensile modulus at different strains as a function of strain rate and empirical fit of Equation 10.

\section{Limitations at high-rates}

At high strain rates the variance in the measured modulus values increases. To accurately measure modulus, the natural period of the load-cell and connecting components must be short when compared to the rise time of the applied force. If this is not the case then the dynamic response of the load-cell will be too slow and the measured force will not track the applied force. Figure 15 shows the natural oscillations of the load-cell and connecting components after a load is suddenly removed. With this setup the natural period of the loadcell was observed to be approximately $290 \mu \mathrm{s}$. The rise time of the applied force is a function of strain rate and the modulus. At at strain rate of $400 \mathrm{~s}^{-1}$ the rise time to reach the observed overstress of $20 \mathrm{MPa}$ would be $50 \mu \mathrm{s}$, assuming that the modulus can be calculated using 


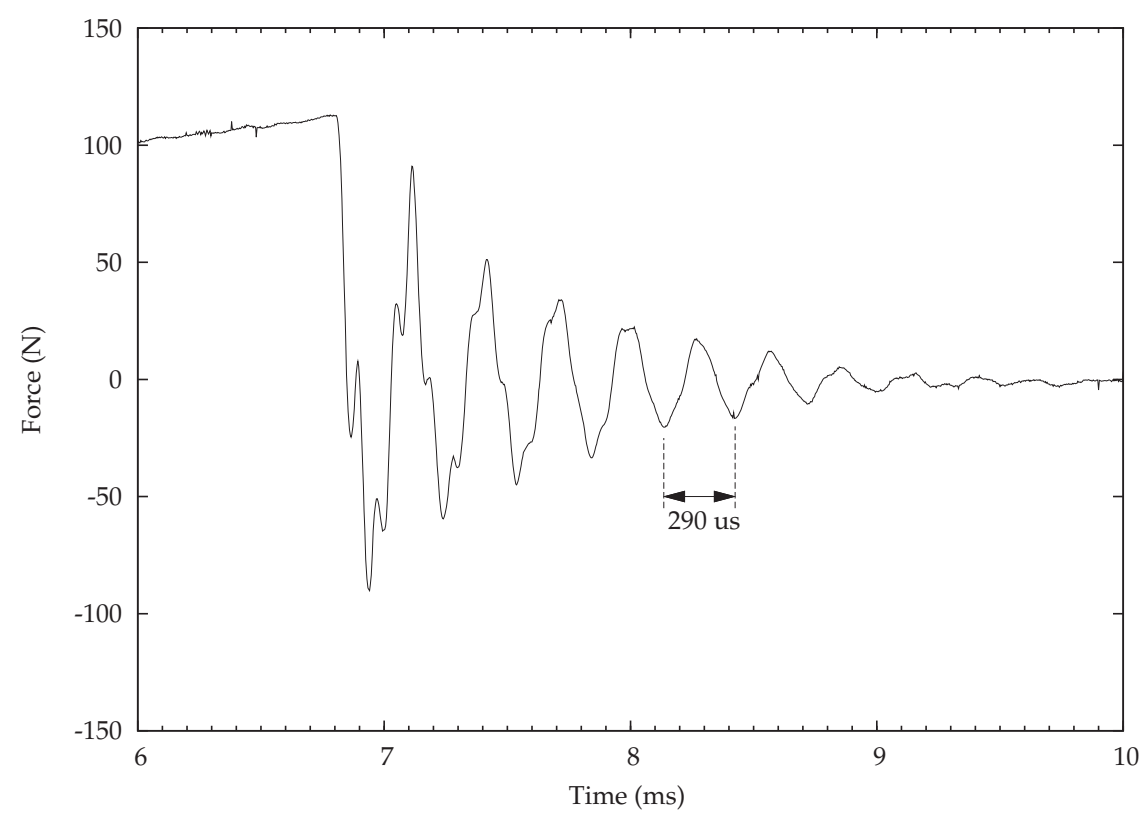

Fig. 15: Unforced vibrations of the load-cell after a load is suddenly removed.

Equation 10. This predicted rise time is approximately one sixth of the natural period of the load-cell and the measured force no longer tracks the applied force, leading to inaccurate modulus values. At a strain rate of $60 \mathrm{~s}^{-1}$ the rise time is approximately twice the natural period of the load-cell and is the practical limit for determining modulus.

Other factors also hinder the measurement of modulus in the small-strain region at high strain rates. Stress waves take a finite amount of time to propagate along the sample length and the sample can only be assumed to be in a uniform state of stress if they can be neglected. To be neglected the waves must decay quickly when compared to the rise time of the applied loading. The wave speed in the sample can be estimated using the relation

$$
c=\sqrt{\frac{E_{0}}{\rho}}
$$


where $\rho$ is the density of PVB. Applicability of this equation is based on the assumption that at high strain rates the material is effectively linear elastic for small strains. Using a modulus of $1 \mathrm{GPa}$ for a test at a strain rate of $400 \mathrm{~s}^{-1}$ and a density of $1100 \mathrm{~kg} / \mathrm{m}^{3}$, the wave speed in the specimen is in the order of $1000 \mathrm{~m} / \mathrm{s}$. For a $40 \mathrm{~mm}$ long specimen (distance between grips) the stress wave at the start of loading would take $40 \mu$ s to propagate down the sample. This propagation time is almost equal to the estimated rise time at a strain rate of $400 \mathrm{~s}^{-1}$. Typically the stress wave will propagate up and down the sample several times, depending on damping characteristics, before it has decayed to a level where dynamic equilibrium can be assumed. The stress and strain in the sample will therefore not be uniform in the smallstrain region for the higher strain rate tests and the calculated modulus may be inaccurate. At a strain rate of $60 \mathrm{~s}^{-1}$ the wave speed can be calculated as approximately $600 \mathrm{~m} / \mathrm{s}$ if Equation 10 is used to determine modulus. At this speed the wave would travel the length of the sample seven times during the rise time, giving the wave enough time to decay so that dynamic equilibrium can be assumed before the end of the small-strain region.

The high-speed camera frame rate also limits the measurable modulus at high strain rates. At the highest rate of $400 \mathrm{~s}^{-1}$ the frame rate used was $15 \mathrm{kHz}$, giving strain values every $66 \mu$ s. If the stress rises from $0 \mathrm{MPa}$ to $20 \mathrm{MPa}$ in the inter-frame time, the maximum modulus that can be determined is approximately $800 \mathrm{MPa}$ for a strain rate of $400 \mathrm{~s}^{-1}$. To capture the modulus in the small-strain region, the frame interval should be at most half the rise time of the input force.

Modulus at $20 \%$ strain

The modulus calculated at $20 \%$ strain, $E_{20 \%}$, is also shown in Fig. 14 . The calculated values vary between about $7 \mathrm{MPa}$ and $10 \mathrm{MPa}$ over the range of tested strain rates. The peak modulus was observed at a strain rate of $8 \mathrm{~s}^{-1}$ and the values decrease at a similar rate for 
both higher and lower strain rates. The variance in calculated modulus also increases at high strain rates for the same reasons discussed in the small-strain modulus section.

\section{Failure stress and strain}

Stress and strain at failure are presented in Fig. 16 as a function of strain rate. The failure stress shows a small increase as the strain rate increases. At $0.2 \mathrm{~s}^{-1}$ the mean failure stress was $30 \mathrm{MPa}$ and at $400 \mathrm{~s}^{-1}$ the mean failure stress was found to have increased to $38 \mathrm{MPa}$. The increasing failure stress can be approximated by the expression

$$
\sigma_{\mathrm{f}}=m_{\sigma} \log \left(\frac{\dot{\varepsilon}}{\dot{\varepsilon}_{0}}\right)+\sigma_{\mathrm{f}, 0}
$$

where $m_{\sigma}$ is the increase in failure stress per decade of strain rate and $\sigma_{\mathrm{f}, 0}$ is the failure stress at a reference strain rate $\dot{\varepsilon}_{0}$. These constants were determined using nonlinear regression and were found to be $m_{\sigma}=2.58 \pm 0.3 \mathrm{MPa}$ per decade and $\sigma_{\mathrm{f}, 0}=30.6 \pm 0.6 \mathrm{MPa}$ for a reference strain rate, $\varepsilon_{0}$, of $1 \mathrm{~s}^{-1}$.

Failure strain values varied between $200 \%$ and $225 \%$. The failure strain was found to decrease slightly over the tested strain rate range of $0.2 \mathrm{~s}^{-1}$ to $400 \mathrm{~s}^{-1}$. An expression similar to that for the failure stress can be used to approximate failure strain

$$
\varepsilon_{\mathrm{f}}=m_{\varepsilon} \log \left(\frac{\dot{\varepsilon}}{\dot{\varepsilon}_{0}}\right)+\varepsilon_{\mathrm{f}, 0}
$$

where $m_{\varepsilon}$ is the change in failure strain per decade of strain rate and $\varepsilon_{\mathrm{f}, 0}$ is the failure strain at a reference strain rate $\dot{\varepsilon}_{0}$. These constants were determined using nonlinear regression and where found to be $m_{\varepsilon}=-0.05 \pm 0.02$ per decade and $\varepsilon_{\mathrm{f}, 0}=2.2 \pm 0.04$ for a reference strain rate of $1 \mathrm{~s}^{-1}$. 


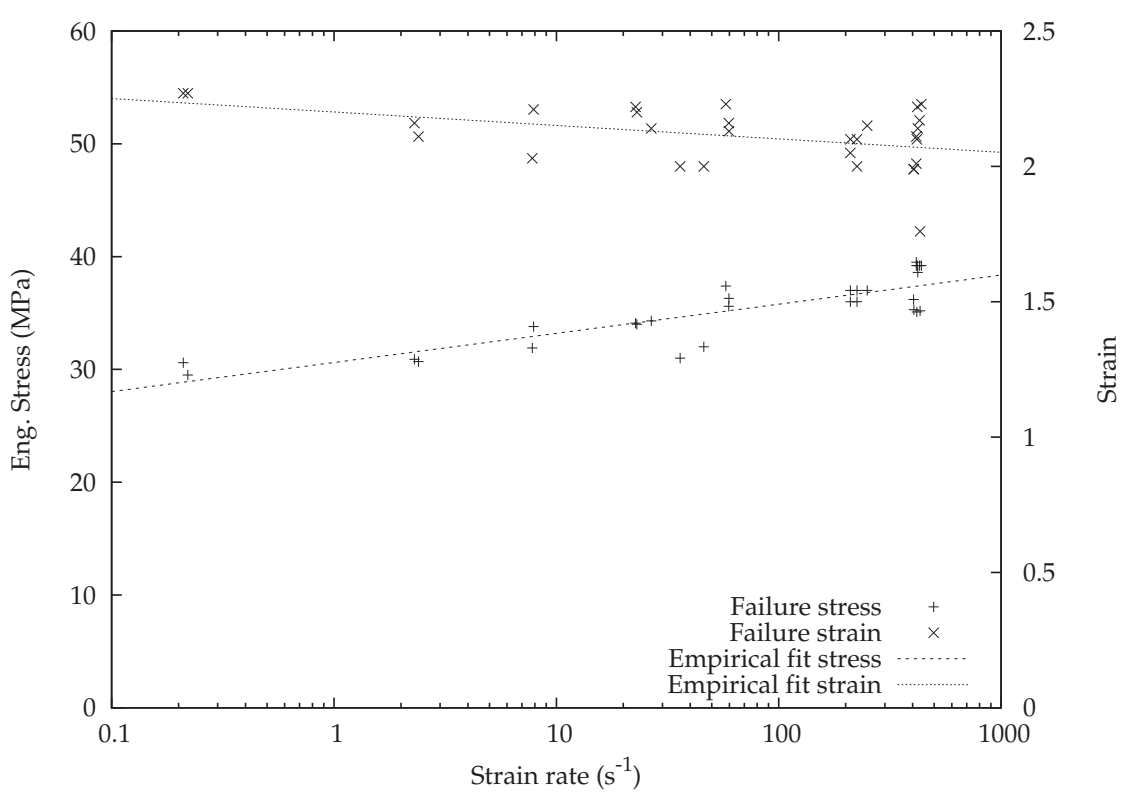

Fig. 16: Semi-log plot of failure stress and strain vs strain rate and empirical fits of Equations 12 and 13.

\section{Overstress}

The overstress, calculated at the intersection between $E_{0}$ and $E_{20 \%}$, is shown as a function of strain rate in Fig. 17. The overstress can be thought of as the contribution of viscosity in the small-strain region. At at a strain rate of $0.2 \mathrm{~s}^{-1}$ the observed overstress was approximately 1.3 MPa. At the highest strain rate of $400 \mathrm{~s}^{-1}$ the overstress increased to $19 \mathrm{MPa}$. This order of magnitude increase in overstress is much greater than the increase in failure stress, indicating that the effect of strain rate is more pronounced at small strains than at large strains. An empirical cube root expression of the form

$$
\sigma_{\mathrm{ov}}=\sigma_{\eta}\left(\frac{\dot{\varepsilon}}{\dot{\varepsilon}_{0}}\right)^{1 / 3}
$$




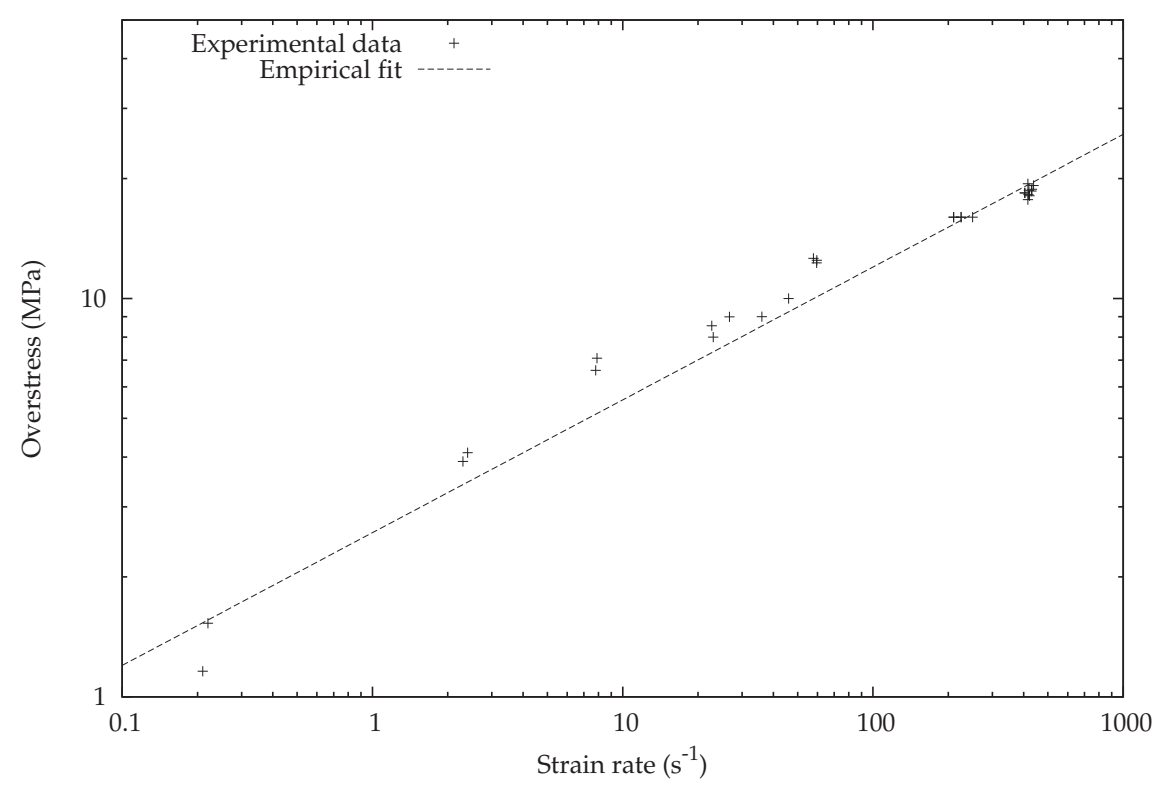

Fig. 17: Log-log plot of overstress as a function of strain rate and empirical fit of Equation 14.

was fitted to the data using non-linear regression where $\sigma_{\eta}=2.58 \pm 0.04 \mathrm{MPa}$ and is the overstress at a reference strain rate $\dot{\varepsilon}_{0}$ of $1 \mathrm{~s}^{-1}$. This empirical fit is shown on Fig. 17. The observed data remains within $20 \%$ of this empirical fit except for one value recorded at $0.2 \mathrm{~s}^{-1}$ and both values recorded at a strain rate of $8 \mathrm{~s}^{-1}$.

True stress

At high levels of strain the engineering stress is not an accurate measure of stress in the material due to changes in cross-sectional area. Many hyperelastic constitutive material models describe the material response in terms of true stress and the stretch ratio. As no necking was observed, the true stress can be found from engineering stress by assuming that there is no change in volume of the deformed material. Under the condition of constant volume 


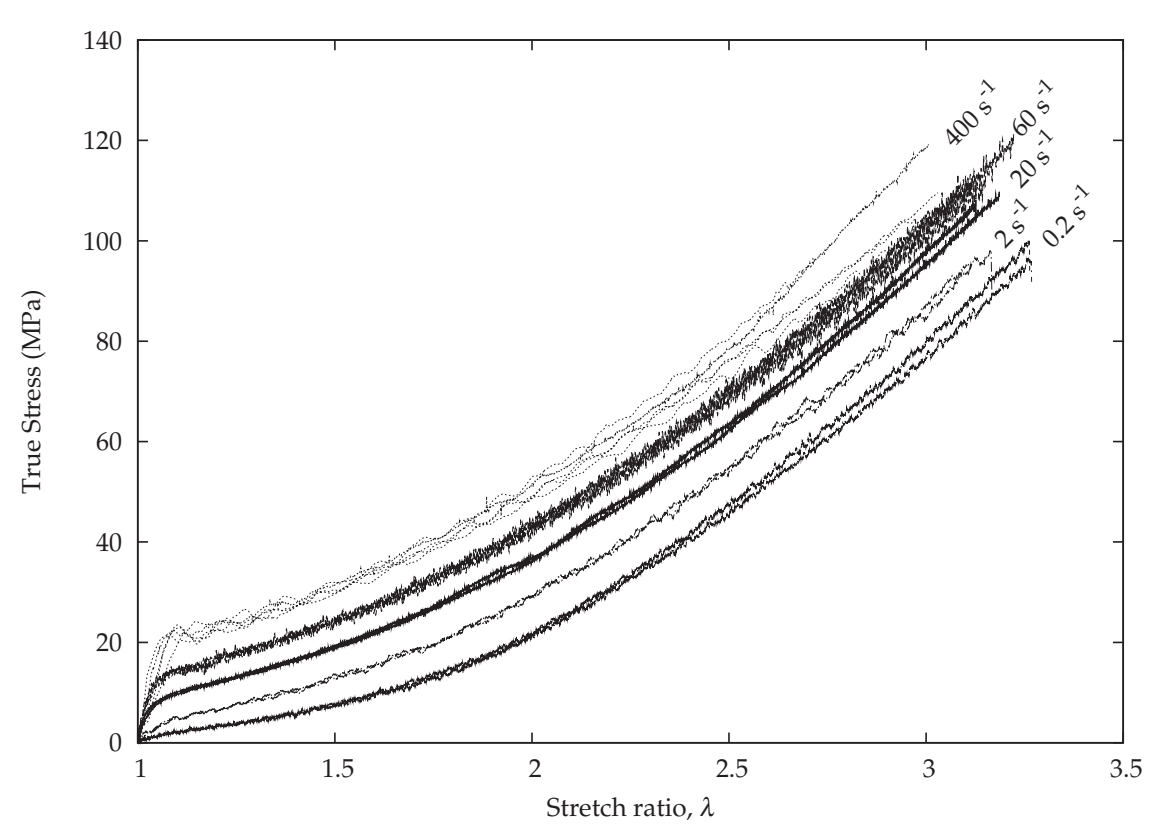

Fig. 18: Summary of true stress vs stretch ratio at different strain rates.

an increase in length of stretch ratio $\lambda$ will result in a reduction in cross sectional area of $1 / \lambda$. The true stress, $\sigma_{\mathrm{t}}$, is therefore equal to the engineering stress multiplied by the stretch ratio . Figure 18 shows true-stress vs stretch ratio curves at strain rates between $0.2 \mathrm{~s}^{-1}$ and $400 \mathrm{~s}^{-1}$.

\section{Discussion}

Small-strain behaviour and temperature effects

The small-strain behaviour of PVB is of primary interest in the bending response of laminated glass. In an uncracked laminate the maximum strain in the PVB interlayer is limited to below the failure strain of the glass plies. The strain to failure of the glass plies is approximately $0.1 \%$ if a failure strength of $80 \mathrm{MPa}$ and an elastic modulus of $72 \mathrm{GPa}$ [10] are 
assumed. However, the PVB interlayer is not likely to experience strain of this magnitude in the uncracked response phase because the predominant mode of deformation is in bending. Under such conditions the PVB interlayer lies on the neutral axis where its main function is to transfer horizontal shear force and maintain the separation distance between the glass plies.

The amount of horizontal shear force that is transferred will depend on the shear modulus and therefore strain rate and temperature. At high deformation rates, or low temperatures, the PVB will be able transfer a significant amount of shear force between the glass plies and the laminated pane will have a bending stiffness of similar magnitude to an equivalent monolithic pane of the same overall thickness. At slow deformation rates, or high temperatures, the PVB will not transfer a significant amount of shear stress and its only function will be to separate the glass plies. Under these conditions the laminate will behave as two independent glass layers with twice the stiffness of one ply on its own. These two extremes were first investigated by Norville et al. [11]. The generalized Maxwell viscoelastic material model calibrated here allows the effect of time and temperature to be taken into account when considering the shear transfer across the PVB interlayer.

Figure 19 compares the data acquired in this paper for a Solutia Saflex PVB interlayer against data published by van Duser et al. [2] on a DuPont Butacite interlayer. The two curves share a similar shape and the moduli in the glassy and rubbery region are of the same orders of magnitude. However, the Butacite curve is shifted by almost two decades towards longer time scales. Comparing the storage modulus vs temperature curves of the two materials shows that Butacite's glass transition temperature $T_{\mathrm{g}}$ is approximately $5^{\circ} \mathrm{C}$ to $10^{\circ} \mathrm{C}$ higher than that of Saflex. Referring to the shift factors in Fig. 10 shows that a difference of $5^{\circ} \mathrm{C}$ to $10^{\circ} \mathrm{C}$ corresponds to a shift of one to two decades in time and therefore accounts for the observed shift. Manufacturers vary the quantity of plasticiser added to the PVB resin 


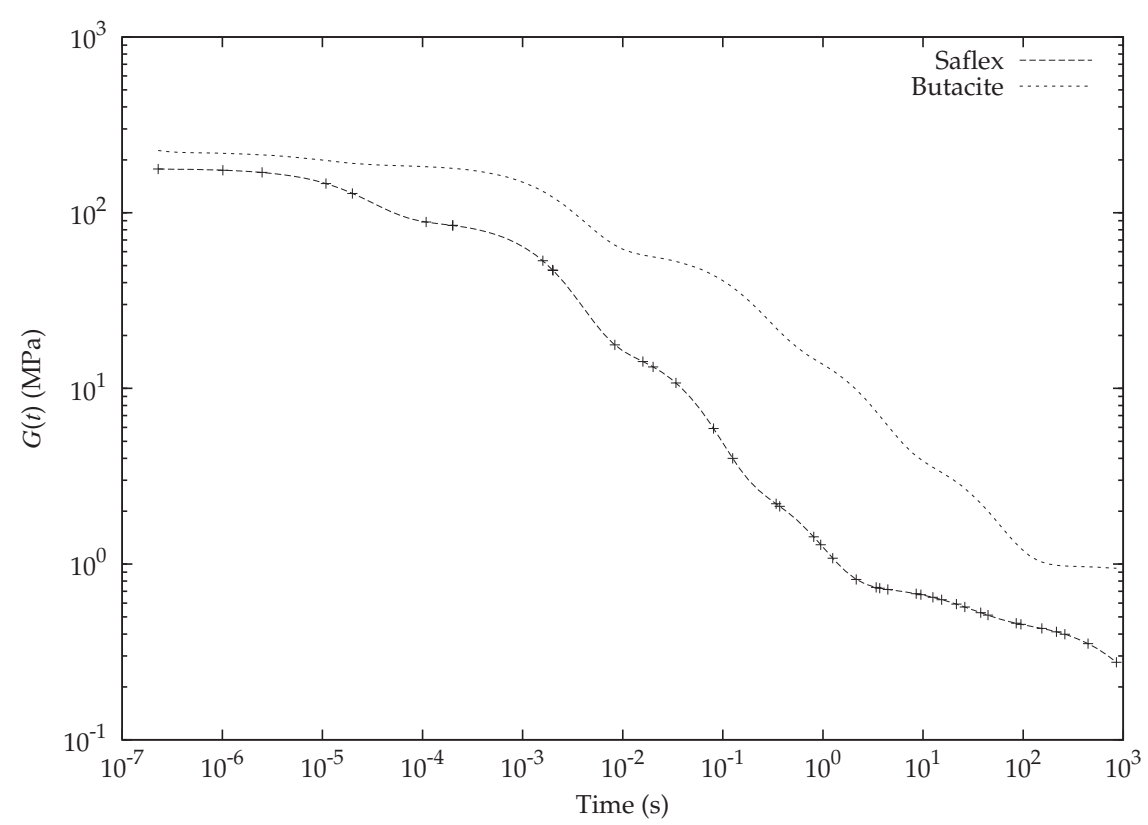

Fig. 19: Comparison of shear relaxation curves between Butacite and Saflex PVB at $20^{\circ} \mathrm{C}$.

to control the $T_{\mathrm{g}}$ of the material for different commercial markets. This is likely to be the cause of the difference observed here. The variation of $T_{\mathrm{g}}$ between interlayer manufactures needs to be considered when analysing the response of laminated glass because the transition region lies within the expected operating temperature range. A higher $T_{\mathrm{g}}$ will lead to a stiffer interlayer which may be of benefit in an uncracked laminated pane. However, it may be detrimental in a cracked pane of laminated glass as it may lead to brittle behaviour and premature failure of the interlayer at high strain-rates.

The small-strain modulus $E_{0}$ can be compared qualitatively with the tensile storage modulus $E^{\prime}$ using the relation between frequency and strain rate given in Equation 9. The smallstrain modulus varied between $28 \mathrm{MPa}$ and $300 \mathrm{MPa}$ over an equivalent angular frequency range of $0.32 \mathrm{rad} / \mathrm{s}$ to $32 \mathrm{rad} / \mathrm{s}$. The frequency range to produce the same tensile storage modulus values was between approximately $10 \mathrm{rad} / \mathrm{s}$ and $1000 \mathrm{rad} / \mathrm{s}$. Although these values are over 

curve in the transition region matches that of the enpirical fit used to describe the smatlcurve in the transition region matches that of the empirical fit used to describe the smallstrain modulus. The tensile storage modulus $E^{\prime}$ was reduced to a reference temperature of $20^{\circ} \mathrm{C}$ whereas the small-strain modulus was measured at a temperature of $25 \pm 3^{\circ} \mathrm{C}$. The shift in frequency is of the same direction and magnitude as though the storage modulus were measured at a temperature of $25^{\circ} \mathrm{C}$.

Low strain rate large-strain behaviour

At a strain rate $0.2 \mathrm{~s}^{-1}$ the small-strain modulus $E_{0}$ approaches the same value as the modulus at $20 \%$ strain, $E_{20 \%}$. The stress-strain curve at this strain rate is of similar form to that of a hyperelastic material. Common constitutive models for hyperelastic behaviour include the Gent [12], Arruda-Boyce [13] and van der Waals models [14]. These models have been used by Muralidhar et al. [15] to consider the bridging behaviour in cracked laminates. Figure 20 compares a non-linear regression fit of the three models against the experimental data at $0.2 \mathrm{~s}^{-1}$. All three models show good agreement with the experimental data at this strain rate. The Gent and Arruda-Boyce curves are almost indistinguishable over this range. Whilst these models show good agreement at this strain rate they do not take into account the time dependent component of the material response. They are unable to capture the high initial modulus observed at higher strain rates. Even at a strain rate of $0.2 \mathrm{~s}^{-1}$ hysteresis and stress relaxation effects will be ignored by these models. Modelling the large-strain behaviour of PVB with a hyperelastic model is therefore of limited value.

\section{Time dependent large-strain behaviour}

The nonlinear viscoelastic behaviour of some elastomers and polymers can be captured by assuming that the stress can be represented by a separable equation of the form 


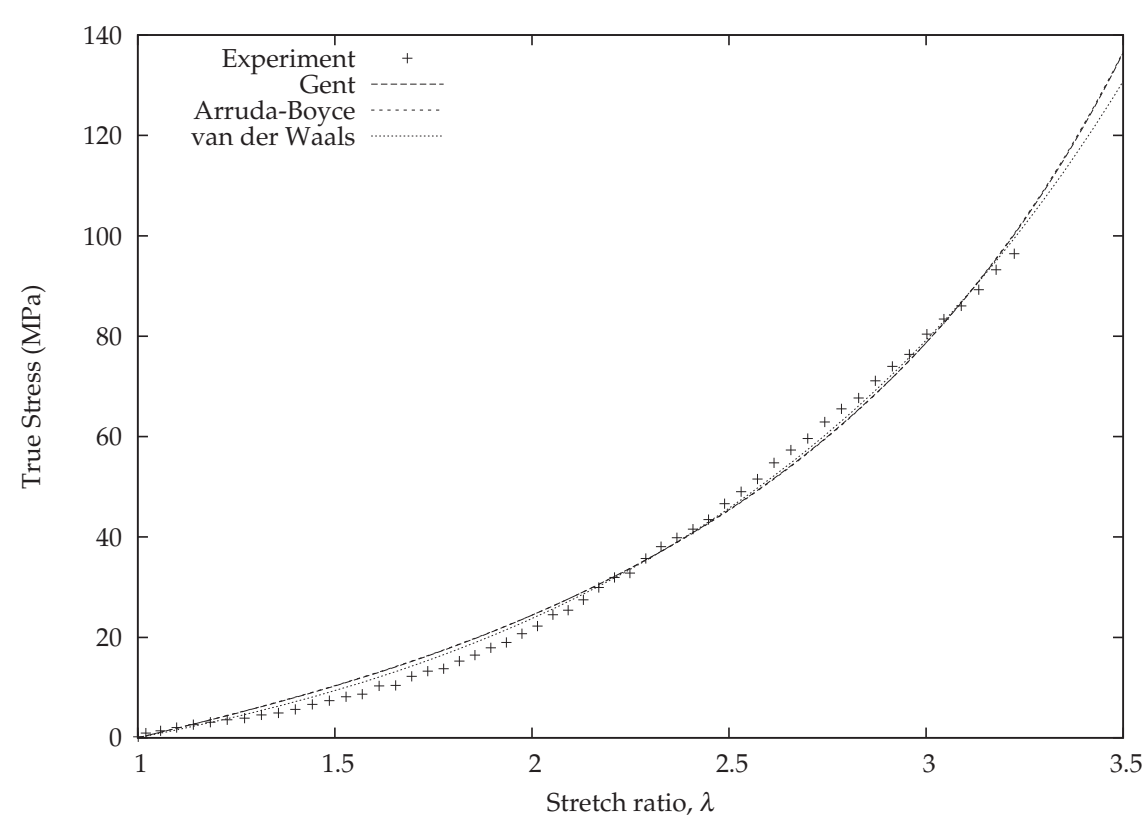

Fig. 20: Comparison of hyperelastic material models with an experiment at a strain rate of $0.2 \mathrm{~s}^{-1}$

$$
\sigma(\lambda, t)=f(\lambda) g(t)
$$

where $f(\lambda)$ and $g(t)$ are stretch and time dependent functions respectively. The function $f(\lambda)$ is usually represented by a hyperelastic material model and $g(t)$ is defined using a Prony series of the form

$$
g(t)=g_{\infty}+\sum_{i=1}^{N} g_{i} e^{-t / \tau_{i}}
$$

where $g_{\infty}$ and $g_{i}$ are dimensionless constants and $\tau_{i}$ are relaxation times. This form of representing nonlinear viscoelastic behaviour is commonly employed in finite element packages such as Abaqus [14]. For Equation 15 to be applicable to a material the stretch 


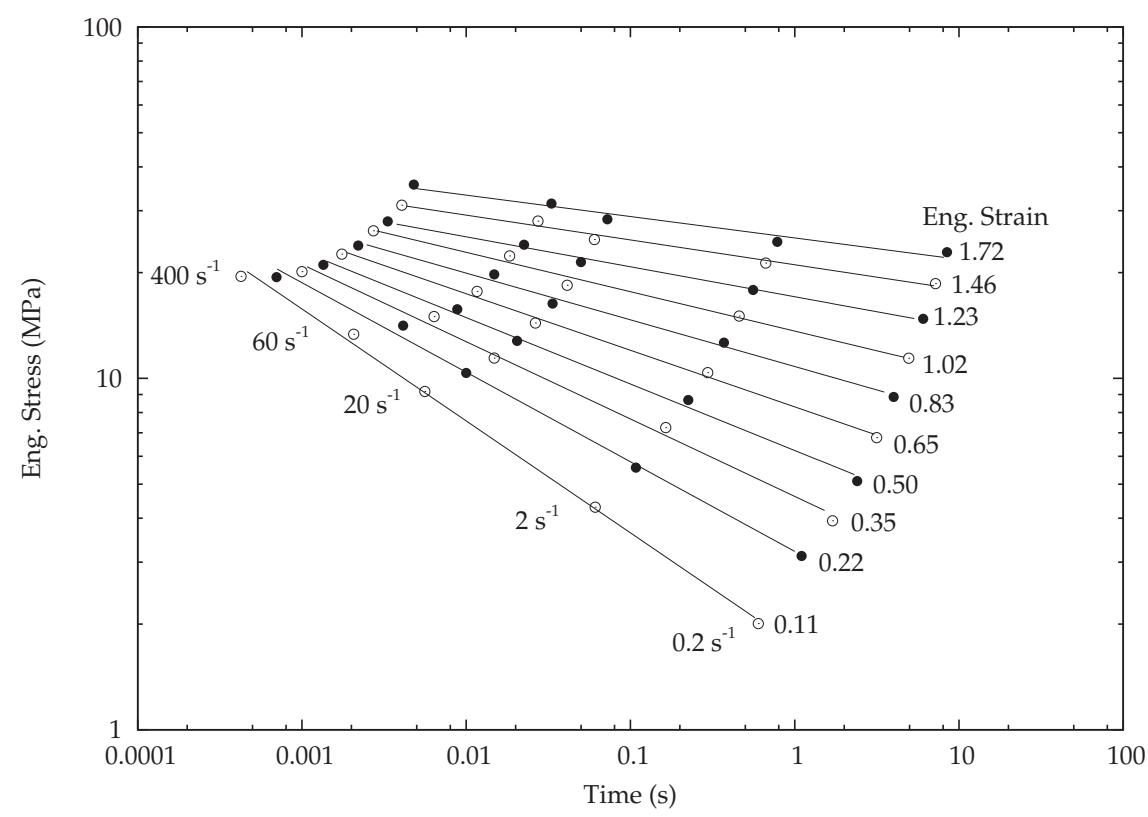

Fig. 21: Log-log plot of stress vs time for different levels of strain.

and time dependent components of the material response need to be separable. Smith [16] devised a simple method for determining whether this is the case for materials loaded at constant strain rates. He suggested that if stress vs time curves are plotted on logarithmic axes for different strain rate tests, lines of constant strain would be parallel if the material can be represented by Equation 15 .

Figure 21 shows lines of constant strain overlaid on stress vs time curves for five samples tested at strain rates from $0.2 \mathrm{~s}^{-1}$ to $400 \mathrm{~s}^{-1}$. It can clearly be seen that the lines of constant strain are not parallel at engineering strains below 1.2 and therefore Equation 15 cannot be used to represent the nonlinear viscoelastic behaviour of PVB over this range. At low strains the constant strain line has a steeper gradient than that at high strains. This indicates that effect of time is more pronounced at low strains than at high strains. 
Recent constitutive models proposed by Hoo Fatt and Ouyang $[17,18]$ have attempted to describe the large-strain behaviour of Styrene Butadiene Rubber (SBR) at high strain rates. SBR, like PVB, shows an initially high modulus at small strains for high strain rates and a lower modulus at large strains. Their model consists of a low stiffness hyperelastic spring in parallel with a high initial stiffness hyperelastic spring and a nonlinear damper. At low strain rates the behaviour tends towards that of the low stiffness hyperelastic spring. At high strain rate the behaviour tends towards that of the combined stiffness of both springs. The assumed hyperelastic function was empirical and was chosen to provide a smooth fit to the observed SBR data. The viscosity function was also an empirical relation that was dependent on the strain and strain rate, rather than being based on the underlying structure of the material. It was found that the hyperelastic function was capable of describing PVB stress-strain response at low strain rates. However, the model was unable to capture the high initial modulus seen in the high strain rate tests accurately. Calibration of the model was also complex, requiring four constants to describe the behaviour of both hyperelastic springs and seven constants to describe the damping function.

The lack of a physically based constitutive model that completely describes the behaviour of PVB at all strains and strain rates means that it is not currently possible to model the behaviour of cracked laminated glass on the level of individual cracks. This does not mean that an empirical model of the global behaviour of cracked laminated glass cannot be developed. One such approach in the modelling of blast loaded laminated glass is described by Hooper et al. [19]. 


\section{Conclusions}

This paper describes an experimental investigation into the behaviour of PVB at different strain rates and strain magnitudes. The small-strain viscoelastic behaviour has been measured using DMA. It was found that the PVB tested had a glassy tensile modulus of the order of $1 \mathrm{GPa}$ and a rubbery modulus of the order of $1 \mathrm{MPa}$. The PVB showed a transition between the two moduli over a temperature range of $5^{\circ} \mathrm{C}$ to $40^{\circ} \mathrm{C}$. A generalized Maxwell model was found to provide an accurate description of the shear relaxation modulus at time scales ranging from $10^{-8} \mathrm{~s}$ to $10^{3} \mathrm{~s}$ for small strains.

Differences in glass transition temperature in PVB produced by different manufacturers were identified. DuPont Butacite had a glass transition temperature approximately $5^{\circ} \mathrm{C}$ to $10^{\circ} \mathrm{C}$ higher than that of Saflex PVB produced by Solutia. A temperature shift of $\pm 5^{\circ} \mathrm{C}$ about a reference temperature of $20^{\circ} \mathrm{C}$ was found to be equivalent to a decade shift in frequency. A low operating temperature would therefore result in a stiffer interlayer, possibly leading to brittle behaviour at high strain rates.

The large-strain tensile behaviour of PVB was investigated using a high-speed servohydraulic testing machine. It was found that the engineering stress at failure varied from $30 \mathrm{MPa}$ at a strain rate of $0.2 \mathrm{~s}^{-1}$ to $38 \mathrm{MPa}$ at $400 \mathrm{~s}^{-1}$. These correspond to a true stress at failure of 95MPa and 120 MPa respectively due a reduction in cross sectional area. The strain to failure was found to vary between $225 \%$ and $200 \%$, showing a slight reduction over the same strain rate range. A small-strain modulus was also determined from the large-strain tensile tests. Moduli between the DMA and large-strain tests were qualitatively similar, tending towards a tensile modulus of $1 \mathrm{GPa}$ at short time scales. Differences in test temperature made drawing a direct quantitative comparison difficult. 
The overstress in the large-strain tensile test was found to vary between $1.3 \mathrm{MPa}$ and $19 \mathrm{MPa}$ over a strain rates range of $0.2 \mathrm{~s}^{-1}$ to $400 \mathrm{~s}^{-1}$. After the initial sharp increase in stress at small strains the curves at all strain rates showed the same general form, similar to that of a hyperelastic material. The influence of time effects on the stress were found to be larger at small strains. No current model completely captures the large-strain timedependent behaviour of PVB, making it difficult to develop a physically based model of the behaviour of cracked laminated glass on the level of individual cracks. However, this does not mean that an empirical model of the global behaviour of cracked laminated glass cannot be developed.

Acknowledgements The authors acknowledge the Engineering and Physical Sciences Research Council (EPSRC) and Arup for financially supporting Dr Paul Hooper. We acknowledge the many constructive discussions with David C. Smith, Ryan A. M. Sukhram and David Hadden of Arup.

\section{References}

1. S.J. Bennison, A. Jagota, C.A. Smith, Journal of the American Ceramic Society 82, 1761 (1999)

2. A. van Duser, A. Jagota, S.J. Bennison, Journal of Engineering Mechanics 125(4), 435 (1999). DOI 10.1061/(ASCE)0733-9399(1999)125:4(435)

3. M.L. Williams, R.F. Landel, J.D. Ferry, Journal of the American Chemical Society 77(14), 3701 (1955). DOI 10.1021/ja01619a008

4. J.D. Ferry, Viscoelastic properties of polymers, Thrid edn. (John Wiley \& Sons, 1980)

5. BS ISO 37:2005, Rubber, vulcanized or thermoplastic. Determination of tensile stress-strain properties. (British Standards Institute, London, 2005)

6. G. Bradski, A. Kaehler, Learning OpenCV (O’Reilly Media, 2008)

7. B.D. Lucas, T. Kanade, in Proceedings of the 1981 DARPA Imaging Understanding Workshop (1981), pp. $121-130$

8. L.R.G. Treloar, The physics of rubber elasticity (Oxford University Press, London, 1975) 
9. P.K. Freakley, A.R. Payne, Theory and practice of engineering with rubber (Applied Science Publishers, 1978)

10. D. Cormie, G. Mays, P. Smith (eds.), Blast effects on buildings, Second edn. (Thomas Telford, 2009)

11. H.S. Norville, K.W. King, J.L. Swofford, Journal of Structural Engineering 124(1), 46 (1998). DOI 10.1061/(ASCE)0733-9399(1998)124:1(46)

12. A.N. Gent, Rubber chemistry and technology 69, 59 (1996)

13. E.M. Arruda, M.C. Boyce, Journal of the Mechanics and Physics of Solids 41, 389 (1993)

14. Dassault Systmes Simulia Corp., Providence, RI, 2009, Abaqus theory manual v6.9

15. S. Muralidhar, A. Jagota, S.J. Bennison, S. Saigal, Acta Materialia 48, 4577 (2000)

16. T.L. Smith, Transactions of the Society of Rheology 6, 61 (1962)

17. M.S.H. Fatt, X. Ouyang, International Journal of Solids and Structures 44, 6491 (2007)

18. M.S.H. Fatt, X. Ouyang, Mechanics of Materials 40, 1 (2008)

19. P.A. Hooper, R.A.M. Sukhram, B.R.K. Blackman, J.P. Dear, International Journal of Solids and Structures Accepted (2011) 